\title{
Efficacy of Class C Fly Ash as a Stabilizer for Marginal Residual Soil
}

\author{
Umar, M. and Alhassan, H. M. \\ Department of Civil Engineering, Faculty of Engineering, Bayero University Kano, Kano State, Nigeria. \\ Corresponding E-mail: mumar.civ@,buk.edu.ng
}

\begin{abstract}
Two laterites samples known for their deficiency in road construction were used to assess the efficacy of Class $C$ fly ash in improving their engineering properties. The two samples were taken from Danbare and Dausayi localities within Kano Metropolis and the fly ash was sourced from the Nigerian Coal Corporation, Enugu. Preliminary tests on the two samples confirmed their deficiency for use in road construction. The processed fly ash was blended with the laterite samples at 0, 3, 6, 9, 12, 15 and 18\%. Hence, the treated soil samples were tested for plasticity, compaction and strength properties. Results obtained revealed reduction in plasticity properties as the fly ash contents increased. Similarly, Maximum Dry Density (MDD) decreased as the fly ash content increased while the Optimum Moisture Content (OMC) of the treated soils increased for the two samples. Peak CBR values of 16 and 35\% were obtained at 9 and $15 \%$ fly ash contents for samples 1 and 2, respectively. The unconfined compression tests showed considerable improvement in strength properties higher than the values of the natural soils. The peak 7 days strength of 630 and $1410 \mathrm{kN} / \mathrm{m}^{2}$ were observed at $12 \%$ and $15 \%$ fly ash content for samples 1 and 2 , respectively.
\end{abstract}

Keywords: Residual soil, Stabilization, Class C fly ash, California Bearing Ratio, Unconfined Compressive Strength.

\section{Introduction}

The exploitation and use of resources for development ultimately results in end products that are disposed of as wastes. The rate at which these end products are generated coupled with environmental issues surrounding waste disposal and the lack of disposal sites within the urban setting have made re-use of disposed materials attractive. Thus, waste items such as incinerator bottom ash, rice husk, bagasse, palm kernel, palm oil fibre among others are beneficially employed by mixing their ashes with other materials to obtain the desired properties from the mixed or blended materials (Umar et al., 2013). Furthermore, fly ash is also disposed of as a by-product of a coal - fired power plant by either sluicing to ponds or at solid waste disposal areas. In view of the perceived composition of fly ash, it has been usefully employed as a pozzolanic material in soil stabilization (Swanepoel and Strydom, 2002).

It was reported by Ahmaruzzaman (2010) that about 0.6 billion tonnes of coal ash is produced annually with fly ash amounting to more than three-quarter of the global ash production. Hence, the disposal of this waste has generated a serious concern in relation to environmental safety. Enormous amount of literature exists on the sources, type, chemical composition and applications of fly ash in engineering practice some of which can be found in the review of fly ash provided by Adriano et al., (1980); Ahmaruzzaman, (2010); Iyer and Scott, (2001). According to ASTM (1994) two classes of fly ash are commonly produced and are referred to as class $\mathrm{C}$ and $\mathrm{F}$ fly ashes. Class $\mathrm{C}$ fly ash is generally pozzolanic, highly cementitious and is usually produced as a by-product of lignite. Class $\mathrm{F}$ is usually produced by burning of anthracite or bituminous coal and is typically pozzolanic. Similarly, fly ash not meeting the requirements in ASTM (1994) is also produced and these are chiefly put to non-concrete applications. Coal ash is popularly used in construction industries for many reasons, some of which include: minimization of disposal costs, freeing land which could have been used as a disposal area for other more important purposes, financial returns from the sale of the by-products and it could also replace some expensive natural resources. Fly ash finds many applications in addition to its 
use as a stabilizer of soils for engineering applications. These may include the utilization of fly ash to replace cement in the production of concrete, light weight aggregate in concrete, structural/land fill material, hydraulic barriers in solid waste containment facility and other related soil improvement applications.

Recent researches suggested the use of class $\mathrm{C}$ fly ash for minimizing sulphate heaves in limestabilized soils (McCarthy et al., 2012). Similarly, Ghosh and Dey (2009) examined the bearing capacity and deformation modulus of soft soil modified with reinforced fly ash and reported the feasibility of constructing roads over soft soils. It was also reported by Chauhan et al., (2008) that strength properties of silty sand soil has substantially improved after it was stabilized with optimum amount of coal ash and fibre. Improvement in strength and reduction in hydraulic conductivity of marginal lateritic soil have been reported by Prabakar et al., (2004); Sezer et al., (2006). A similar study by Cristelo et al., (2012) stabilized a marginal soil with coal ash activated with alkaline to facilitate self-compaction in earth construction. Therefore, this study examines the potentials as well as the efficiency of using fly ash in stabilizing marginal lateritic soils.

\section{Materials and Methods \\ Materials}

Proprietary fly ash sample was supplied by the Nigerian Coal Corporation, Enugu State of Nigeria. Two $50 \mathrm{~kg}$ weight of fly ash were procured. The laterite samples were also obtained from two burrow pits known for their deficiency for road construction. The two burrow pits are located at Danbare (Sample 1) and Dausayi (Sample 2) villages in Kano which are $10 \mathrm{~km}$ and $12 \mathrm{~km}$ from Kano City Centre respectively. The samples were collected at $1.5 \mathrm{~m}$ depth.

\section{Sample preparation}

Air dried soil samples were prepared by adding the required percentage of fly ash content and mixing thoroughly at optimum moisture content of the soil. Portion of the fly ash that passes B. S, sieve No. 200 was used in the sample preparation. Fly ash contents of $0 \%, 3 \%, 6 \%, 9 \%, 12 \%$, $15 \%$ and $18 \%$ by dry weight of the soil were used, with the $0 \%$ fly ash content being used as the control. The amount of water used at each stage of the sample preparation was based on the predetermined optimum moisture content of the soil samples. Hence, the soil specimens were manually prepared and careful steps were followed to have uniform mixtures of the specimens before any experiment.

\section{Index properties}

The index properties of a soil are essentially used in the classification of the soil for engineering applications. In this study, plasticity properties, natural moisture content, grain size analysis and specific gravity tests were conducted for classification purpose.

\section{Compaction test}

Standard Proctor compaction test was carried out to obtain the Optimum Moisture Content (OMC) at which a given soil is compacted to attain its Maximum Dry Density (MDD).

\section{Unconfined Compressive Strength}

This is another form of triaxial test in which the confining pressure is reduced to zero. Thus, the soil specimen was subjected to failure by gradual increase in axial loading. The load frame method was used in determining the compressive strength of the soil specimens. The specimens were cured for 7 days before they were subjected to the Unconfined Compressive Strength tests.

\section{California bearing ratio}

The California bearing ratio (CBR) test is one of the common methods of determining the bearing capacity of subgrade material in pavement design practices. Hence, the soil samples were soaked for 48 hours before they were subjected to CBR testing. 


\section{Results and Discussion \\ Laterite soils}

Index and engineering properties of the soil samples were determined for classification and stabilization purposes. The soil samples were classified as A-7-5(15) and A-6(5) for samples 1 and 2, respectively based on the American Association of State Highway and Transportation Officials (AASHTO) standard. Table 1 presents the summary of the properties of the two soil samples.

Table 1: Index and Engineering properties of the soil samples

\begin{tabular}{lcc}
\hline Properties & Red Laterite & White Laterite \\
& S1 & S2 \\
\hline Nature moisture content (\%) & 11.4 & 5.5 \\
Liquid Limit (\%) & 62.5 & 39.5 \\
Plastic limit (\%) & 30.5 & 26.7 \\
Plasticity Index (\%) & 32.0 & 12.8 \\
Linear shrinkage (\%) & 8.6 & 7.1 \\
Specific Gravity (\%) & 2.87 & 2.53 \\
MDD(Mg/m $\left.{ }^{3}\right)$ & 1.83 & 1.90 \\
OMC (\%) & 9.86 & 8.60 \\
CBR (\%) & 7.0 & 15.0 \\
UCS (kN/m $\left.{ }^{2}\right)$ & 300 & 600 \\
Water erosion (\%) & 10.9 & 12.2 \\
AASHTO Classification & A-7-5 & A-6 \\
Group Index & 15 & 5 \\
Clay proportion (\%) & 46.1 & 44.6 \\
Silt proportion (\%) & 11.0 & 10.5 \\
Percentage passing B.S. No. 200 & 57.1 & 55.1 \\
Colour & Reddish Brown & Light Brown \\
\hline
\end{tabular}

\section{Atterberg limits}

\section{Liquid limit}

It was observed that plasticity properties of the soil decrease as the fly ash content increases. Figure 1 presents the observed changes in liquid limit of the two soil samples as the fly ash content increases. The liquid limit generally decreased at all fly ash contents for the stabilized soil samples. For sample 1, the liquid limit decreased from $55.0 \%$ at $3 \%$ fly ash content to $46.1 \%$ at $18 \%$ fly ash content. Similarly, there was a general decrease from $38.2 \%$ at $3 \%$ fly ash content to $28.4 \%$ at $18 \%$ fly ash content for the liquid limit of sample 2 . The trend generally was that the liquid limit decreases as the fly ash content increases; this can be attributed to the gradual raise in the pozzolanic reactions that aided flocculation of the fine particles as the fly ash contents increased. Thus, the effective grain size of the soil mass now increased due to aggregation of the clay particles. The aggregation converted fine soil particles into coarser particles and this decreases the liquid limit of the soil. This finding is in good agreement with Goswami and Singh (2005). Specifically, the liquid limit decreased to $46.1 \%$ and $28.4 \%$ at $18 \%$ fly ash content for samples 1 and 2 respectively. 


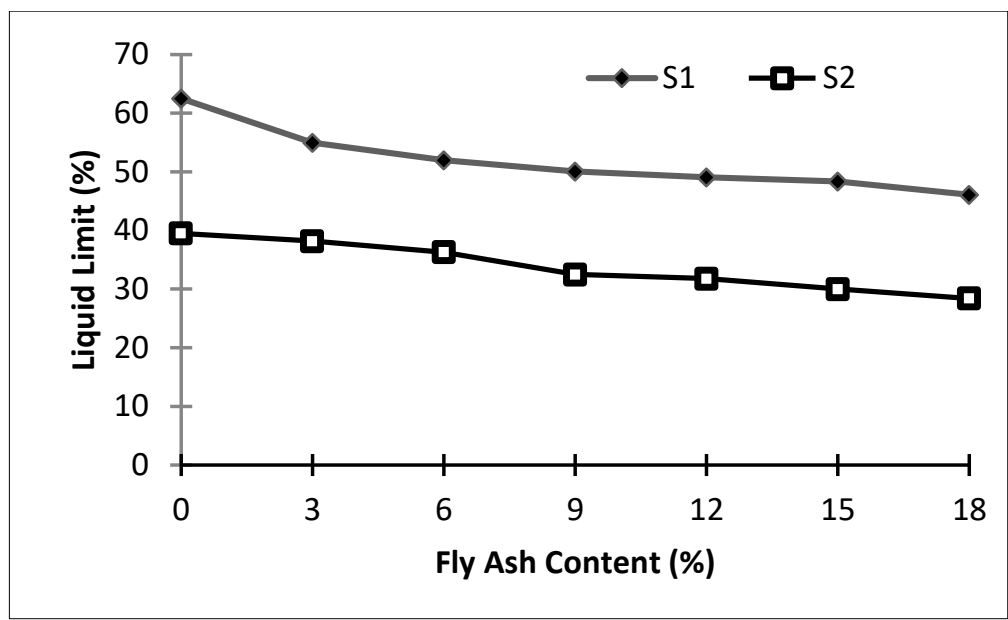

Figure 1: Variation of liquid limit with fly ash content

\section{Plastic limit}

The plastic limits of the natural soils were $30.5 \%$ and $26.7 \%$ for samples 1 and 2 , respectively as shown in Figure 2. For sample 1, there was no regular pattern of variations of plastic limit as the fly ash content increased. However, sample 2 showed greater consistent behaviour in which the plastic limit decreased continuously for all the soil-fly ash combinations; that is from $25.8 \%$ to $18.8 \%$. This may be due to aggregation of the clay content by the fly ash which is a pozzolana as described by Goswami and Singh (2005).

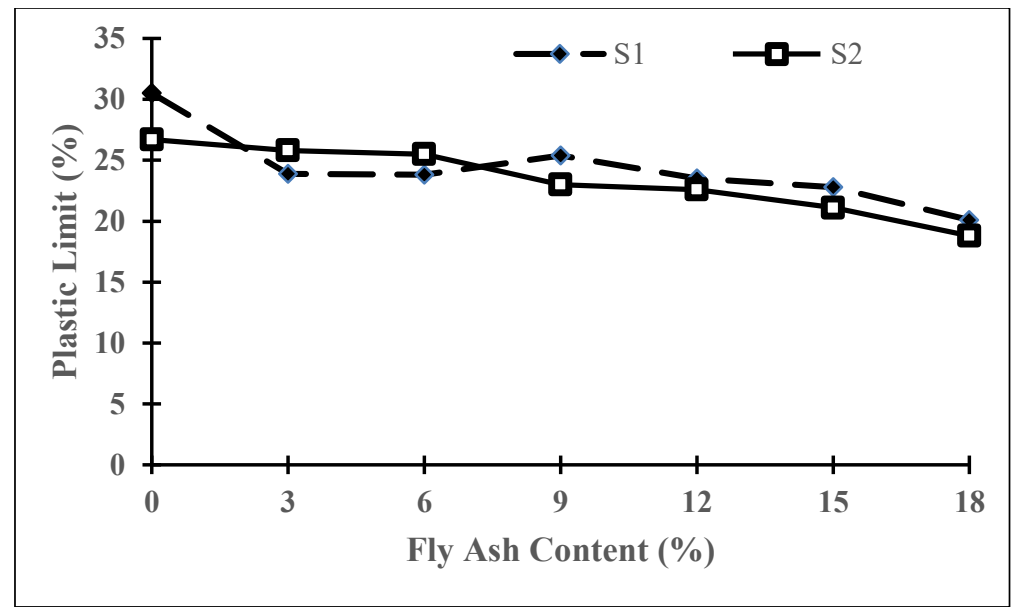

Figure 2: Variation of plastic limit with fly ash content

\section{Plasticity Index}

Figure 3 shows the changes in the plasticity index of the soil at different fly ash contents. This study revealed that, the plasticity index reduces as the fly ash content increases for the two soil samples. Meanwhile, the plasticity index decreased sharply between $6-9 \%$ fly ash content for the stabilized samples, beyond which the decrease became less pronounced for sample 2 and increased at $18 \%$ fly ash content. For sample 1, there was an increase in the plasticity index between $12-18 \%$ fly ash content. Consequently, the general decrease in the plasticity indices at all fly ash contents is an indication of the improvement in the workability of the stabilized soils making them better for use as a construction material (Goswami and Singh, 2005). 


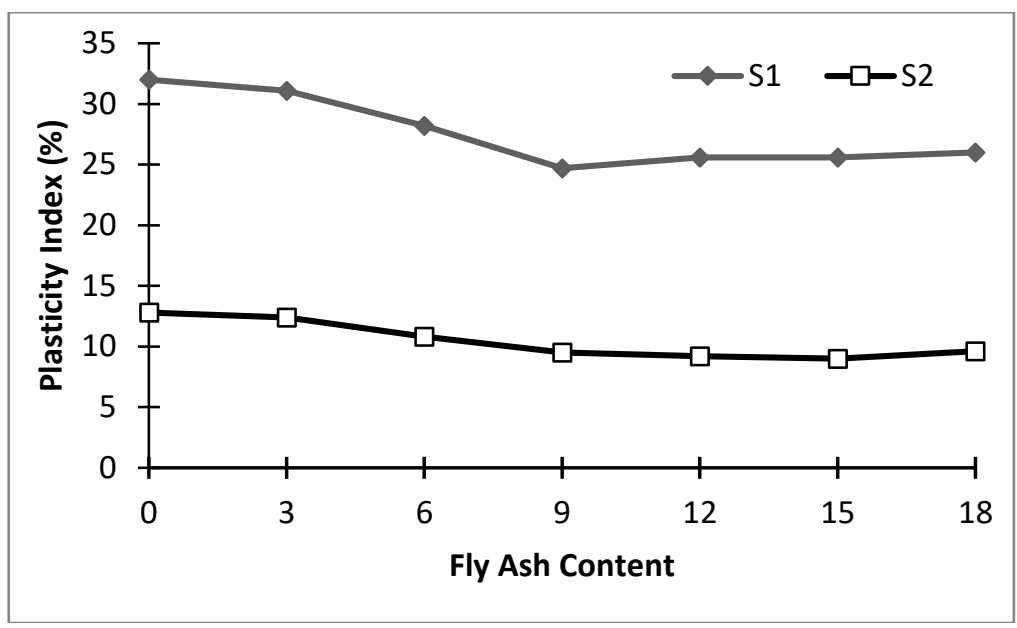

Figure 3: Variation of Plasticity Index with fly ash content

\section{Optimum Moisture Content}

The detailed results of the optimum moisture content of the soil samples at various fly ash contents are shown in Figure 4. The optimum moisture contents of the natural soils are 9.86\% and $8.60 \%$ for samples 1 and 2, respectively. The OMC increases with increase in fly ash content up to $12 \%$ beyond which there was a continuous decrease in the OMC for sample 1. Similarly, for sample 2, the OMC increased with the addition of fly ash content up to $6 \%$, after which the OMC decreased till 12\% fly ash content before rising slightly at $15 \%$ and then decreased again when fly ash content increased from 15 to $18 \%$. Addition of the ash resulted into increase in the fine particles of the soil mass which in turn needed additional quantity of water to enable some reactions between the fly ash and the soil mineral particles; thereby increasing the OMC of the soil. Therefore, more water will be required to lubricate the entire soil and the stabilizer to enhance compaction (Nicholson and Kashyap, 1993).

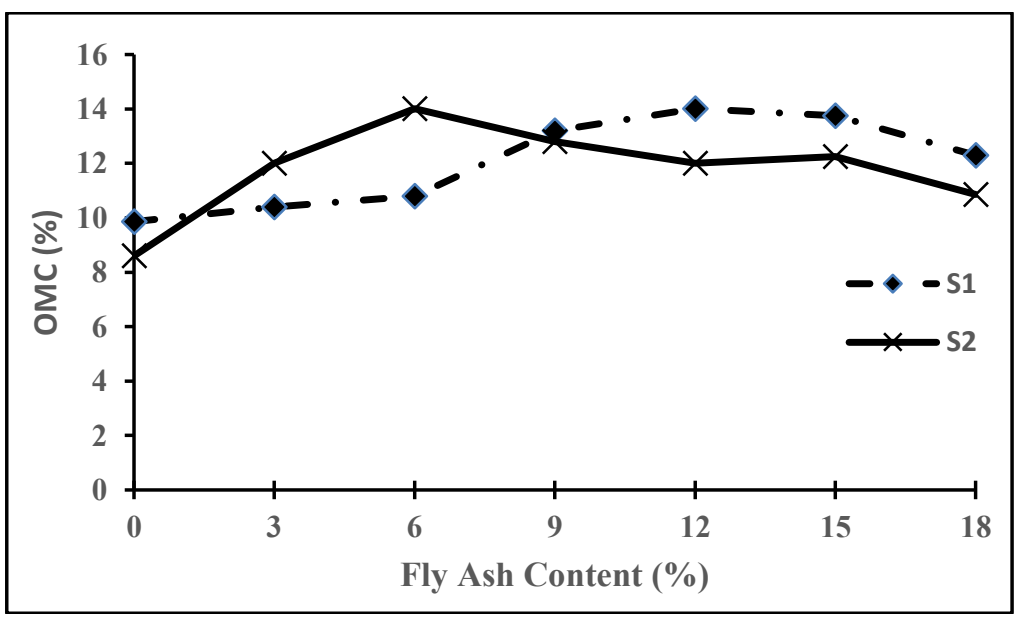

Figure 4: Variation of $\mathrm{OMC}$ with fly ash contents

\section{Maximum Dry Density (MDD)}

The MDD obtained at varying soil - fly ash combinations are presented in Figure 5. The maximum dry densities for the soils are 1.83 and $1.90 \mathrm{Mg} / \mathrm{m}^{3}$ for samples 1 and 2, respectively. The MDD decreased as the fly ash content increased up to $6 \%$ after which it remained constant between 6 and $9 \%$ and the decrease continued from $9-15 \%$ fly ash content after which it increased up to $18 \%$ for sample 1 . The trend is similar for sample 2; the MDD also decreased as a result of the increase in the ash content, after which the decrease remained constant from 9- 
$12 \%$ fly ash content and continued to decrease from $15-18 \%$ fly ash content. Hence, the decrease in dry density is an indication that the stabilized soil can achieve its maximum dry density at lower compactive energy than the natural soil; thereby reducing the cost of compaction (Nicholson and Kashyap, 1993).

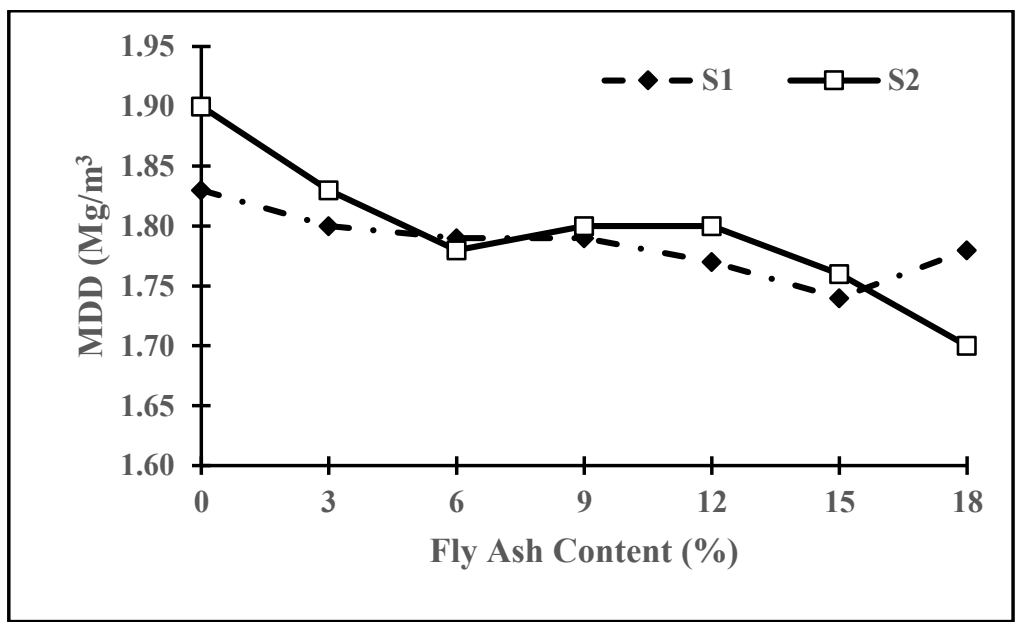

Figure 5: Variation of MDD with fly ash content

\section{California Bearing Ratio (CBR)}

The CBR test results of the natural samples at optimum moisture content are $7 \%$ and $15 \%$ respectively for samples 1and 2. Figure 6 presents the CBR of the two soil samples after the addition of varying proportions of fly ash. It can be deduced from the study that the CBR values increased with the addition of fly ash content for the two samples. For sample 1, there was a general increase in the CBR of the soil treated with fly ash up to $9 \%$. Thereafter, it remained constant up to $12 \%$ fly ash content and then decreased from $12-18 \%$ fly ash content. Whereas, for sample 2, the CBR increased with the addition of fly ash up to $15 \%$ beyond which it decreased. Hence, significant increase in the CBR of more than $100 \%$ was observed for samples 1 and 2 at 9 and $15 \%$ fly ash contents, respectively. This may be attributed to the reactions between the soil and the fly ash that resulted in the formation of cementitious compound that binds the soil particles together, thereby improving the strength (Shaheen et al., 2014). Hence, improvement of marginal lateritic soils using fly ash by cation exchange can be very prospective. This is because fly ash can provide substantial cations that facilitate flocculation of clay particles under ionized conditions (Cokca, 2001).

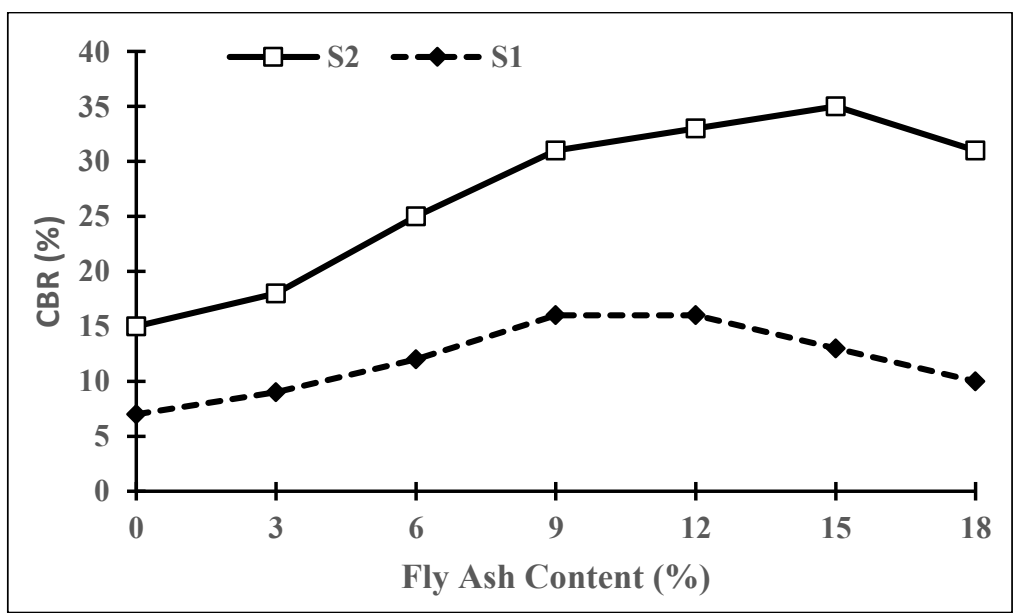

Figure 6: Variation of CBR with fly ash content 


\section{Unconfined Compressive Strength (UCS)}

Figure 7 depicts the correlation between the addition of fly ash and the UCS results of the treated soils. The addition of the fly ash at varying percentages to the soils increased the UCS values up to $15 \%$ fly ash content beyond which it decreased at $18 \%$ for sample 2 . For sample 1 , the increase in the UCS was from $300 \mathrm{kN} / \mathrm{m}^{2}$ at $0 \%$ fly ash content to $630 \mathrm{kN} / \mathrm{m}^{2}$ at $12 \%$ fly ash contents. For sample 2, the UCS increased from $600 \mathrm{kN} / \mathrm{m}^{2}$ at $0 \%$ fly ash content to $1410 \mathrm{kN} / \mathrm{m}^{2}$ at $15 \%$ fly ash content. The strength improvement of fly ash treated soil is ascribed to the soilfly ash reaction which resulted in the creation of cementitious compound that binds the soil aggregates. Generally, it has been established that fly ash could be utilized effectively to treat most coarse and medium-grained soils with PI of not more than $25 \%$ as postulated by Beeghly (2003). Hence, the noticeable improvement in the strength properties of sample 2 having a PI value of $12.8 \%(<25 \%)$ is in good agreement with the findings of Beeghly, 3003. While, for sample 1 having a PI value of $32.0 \%(>25 \%)$, the improvement in strength is not appreciable when compared with that of sample 2 (Sivapullaiah and Jha, 2014).

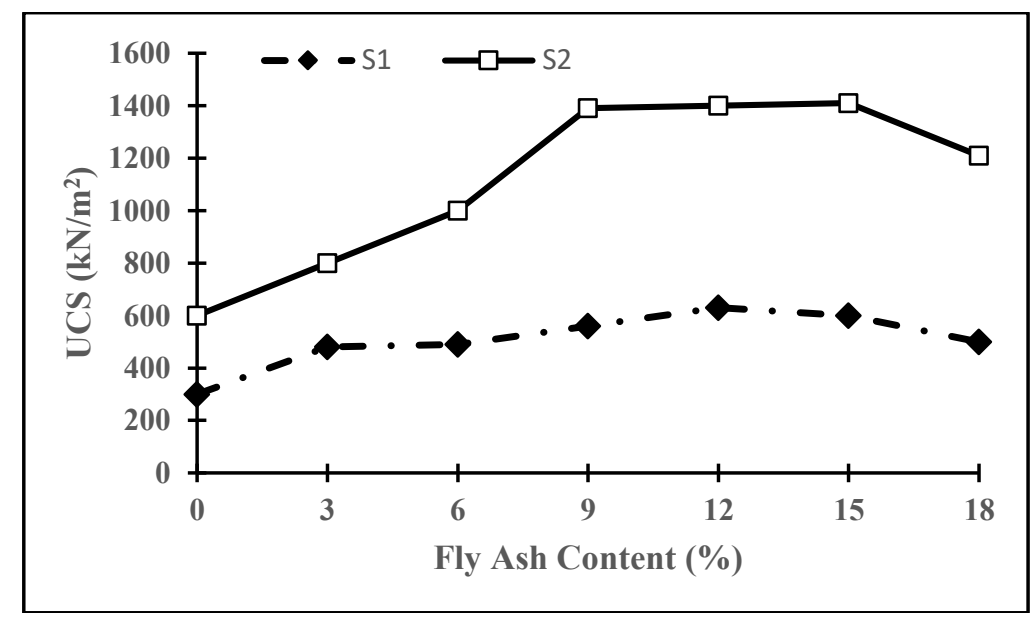

Figure 7: Variation of UCS with fly ash content

\section{Conclusions}

1. The laterite samples used in the study were classified as A-7-5(15) and A-6(5) soils using the AASHTO system. The particle size analysis showed that the soil samples are largely fine-grained with some gravel contents. Thus, the two soil samples in their natural state were found to be unsuitable for some engineering applications.

2. The plasticity properties of the soils reduced as the fly ash percentages increased in the samples. The reduction in the plasticity index was due to the reduction in liquid limit. Specifically, the plasticity indices of the treated samples decreased from $32.0 \%$ to $24.7 \%$ at $9 \%$ fly ash content and from $12.8 \%$ to $9.0 \%$ at $15 \%$ fly ash content for samples 1 and 2 respectively. Hence, an optimum dose may be found between $9-15 \%$ fly ash content to reduce the plasticity of the natural soils.

3. The maximum dry densities of the natural soils were considerably altered due to the addition of fly ash in the soils. The MDD decreased as the fly ash content increased while the OMC of the treated soils increased. Hence, the decrease in the dry densities indicates that, the treated soils need low compactive energy than the natural soils to attain the maximum dry densities at OMC, as such the cost of compaction could be economical.

4. The soil-fly ash combinations showed substantial improvement in the CBR of the soils, particularly at $9 \%$ fly ash content for sample 1 where the peak CBR value of $16 \%$ was 
obtained. Likewise, a peak CBR value of 35\% was also obtained at $15 \%$ fly ash content for sample 2 . Hence, fly ash content of $9-15 \%$ could be used to stabilize these soils.

5. The unconfined compression tests showed considerable improvement in the strength properties of the treated soils. The peak 7-day strength of 630 and $1410 \mathrm{kN} / \mathrm{m}^{2}$ were observed at 12 and $15 \%$ fly ash content for samples 1 and 2 , respectively.

\section{References}

Adriano, D., Page, A., Elseewi, A., Chang, A. and Straughan, I. (1980). Utilization and Disposal of Fly Ash and Other Coal Residues in Terrestrial Ecosystems: A Review 1. Journal of Environmental Quality. 9(3), 333-344.

Ahmaruzzaman, M. (2010). A review on the utilization of fly ash. Progress in energy and combustion science. 36(3), 327-363.

Beeghly, J. H. (2003). Recent experiences with lime-fly ash stabilization of pavement subgrade soils, base and recycled asphalt. Proceedings of the 2003 Proceedings of the International Ash Utilization Symposium, University of Kentucky, Lexingston, USA, Oct, 20-22.

Chauhan, M. S., Mittal, S. and Mohanty, B. (2008). Performance evaluation of silty sand subgrade reinforced with fly ash and fibre. Geotextiles and geomembranes. 26(5), 429435.

Cokca, E. (2001). Use of class c fly ashes for the stabilization of an expansive soil. Journal of Geotechnical and Geoenvironmental Engineering. 127(7), 568-573.

Cristelo, N., Glendinning, S., Miranda, T., Oliveira, D. and Silva, R. (2012). Soil stabilisation using alkaline activation of fly ash for self compacting rammed earth construction. Construction and building materials. 36, 727-735.

Ghosh, A. and Dey, U. (2009). Bearing ratio of reinforced fly ash overlying soft soil and deformation modulus of fly ash. Geotextiles and geomembranes. 27(4), 313-320.

Goswami, R. K. and Singh, B. (2005). Influence of fly ash and lime on plasticity characteristics of residual lateritic soil. Proceedings of the Institution of Civil Engineers - Ground Improvement. 9(4), 175-182.

Iyer, R. and Scott, J. (2001). Power station fly ash - a review of value-added utilization outside of the construction industry. Resources, Conservation and Recycling. 31(3), 217-228.

McCarthy, M., Csetenyi, L., Sachdeva, A. and Dhir, R. (2012). Identifying the role of fly ash properties for minimizing sulfate-heave in lime-stabilized soils. Fuel. 92(1), 27-36.

Nicholson, P. G. and Kashyap, V. (1993). Flyash stabilization of tropical Hawaiian soils. Fly ash for soil improvement. ASCE Geotechnical Special Publication No. 36.

Prabakar, J., Dendorkar, N. and Morchhale, R. (2004). Influence of fly ash on strength behavior of typical soils. Construction and Building Materials. 18(4), 263-267.

Sezer, A., İnan, G., Y1lmaz, H. R. and Ramyar, K. (2006). Utilization of a very high lime fly ash for improvement of Izmir clay. Building and environment. 41(2), 150-155.

Shaheen, S. M., Hooda, P. S. and Tsadilas, C. D. (2014). Opportunities and challenges in the use of coal fly ash for soil improvements-a review. Journal of environmental management. 145, 249-267.

Sivapullaiah, P. V. and Jha, A. K. (2014). Gypsum Induced Strength Behaviour of Fly AshLime Stabilized Expansive Soil. Geotechnical and Geological Engineering. 32(5), 1261-1273.

Swanepoel, J. and Strydom, C. (2002). Utilisation of fly ash in a geopolymeric material. Applied geochemistry. 17(8), 1143-1148.

Umar, M., Alhassan, H., Abdulfatah, A. and Idris, A. (2013). Beneficial use of Class-C Fly Ash in Improving Marginal Lateritic Soils for Road Construction. Electronic Journal of Geotechnical Engineering. 18, 2815-2822. 